\title{
TREATMENT OF DISTILLERIES AND BREWERIES SPENT WASH WASTEWATER
}

\author{
Sohail Ayub ${ }^{1}$, Shoebuddin Usmani ${ }^{2}$ \\ ${ }^{1}$ Associate Professor, Civil Engg. Dept. Aligarh Muslim University (AMU), Aligarh \\ ${ }^{2}$ Assistant Professor CED, Integral University, Lucknow
}

\begin{abstract}
The distillery sector is one of the seventeen categories of major polluting industries in India. These units generate large volume of dark brown colored wastewater, which is known as "spent wash". Liquid wastes from breweries and distilleries possess a characteristically high pollution load and have continued to pose a critical problem of environmental pollution in many countries. The principal pollution effects of the wastewaters of these fermentation industries on a water course are multiple in natures. An attempt has been made to high light the treatment of distillery spent wash by using natural adsorbent. The results obtained herein indicate the feasibility of activated carbon used as an adsorbent for removal of pollutants from distillery spent wash. The results show the significant amount of reduction of pollutants by activated carbon. The study concluded that adsorbent dosage, contact time and effluent dilutions all the three are important parameters affecting the pollutants removal by adsorption.
\end{abstract}

Keywords: Distillery waste water, treatment, activated carbon

\section{INTRODUCTION}

\subsection{The Need for Treating Distillery Effluent}

The distillery sector is one of the seventeen categories of major polluting industries in India. These units generate large volume of dark brown coloured wastewater, which is known as "spent wash". (MoEF).Liquid wastes from breweries and distilleries possess a characteristically high pollution load and have continued to pose a critical problem of environmental pollution in many countries. The principal pollution effects of the wastewaters of these fermentation industries on a water course are multiple in natures. High temperature of the wastewaters may instantaneously kill fish and other aquatic organisms, thus destroying the flora and fauna of a river, when the wastewaters are discharged into it. The most damaging effect of the wastewaters of the fermentation industries, especially distillery, on a stream is caused by high concentration of readily decomposable organic matters present in the waste waters. Due to decomposition of soluble and suspended organic matters present in the wastewaters, high BOD (Biochemical Oxygen Demand) and COD (Chemical Oxygen Demand) of the wastewaters results, causing rapid depletion of the oxygen content of the water, thus creating a foul smell. This further promotes growth of nuisance organisms and can render the stream totally unfit for propagating fish life and for the purpose of drinking, personal hygiene, recreation and other purposes. The distillery effluents, when drained into a water source, make it susceptible for the propagation of harmful microbes. Thus creating serious biological hazards like the generation and propagation of the water borne diseases. This required that the effluents of the distillery are either treated or utilized profitably.

\section{IMPACT OF DISTILLERY EFFLUENT ON ENVIRONMENT}

Following are the impacts of distillery effluent on environment.

- Discharge of wastewater with high TDS would have adverse impact on aquatic life and to make unsuitable water for drinking purpose, if used for irrigation reduce the crop yield ,corrosion in water system and pipe line.

- Suspended solids in wastewater reduce the light penetration and plant production as a result in receiving water by increasing turbidity it can also clog the fish gills.

- High amount of BOD in the wastewater leads to the decomposition of organic matter under the anaerobic condition that produces highly objectionable products including Methane (CH4), Ammonia (NH3), and Hydrogen Sulphide (H2S) gas.

- Low Dissolved Oxygen (DO) in water bodies affect the aquatic life as DO drops fish and other species are threatened and may get killed.

- Fall in DO levels causes undesirable odours, tastes and reduce the acceptability of water for domestic purpose.

- In steam generation, DO is one of the most important factors causing corrosion of the boiler material. 
- Generally, industrial wastewater changes $\mathrm{pH}$ level of the receiving water body. Such changes can affect ecological aquatic system; excessive acidity particularly can result in release of hydrogen sulphide (H2S) to air.

- Alkaline nature of wastewater causes declination in plant growth and crop growth.

- Colour and odour of the effluent of distillery was red brown in colour with unpleasant odour of Indol, Sketol and other sulphur compounds.

- Spent wash is a complex, multi component stream that is known to cause considerable fouling.

\section{ADSORPTION FOR DISTILLERY WASTEWATER TREATMENT}

Adsorption of an adsorbent from a solution is caused by physical and chemical forces. The physical background is produced mainly by Van Der Waals and electrostatic forces, between an adsorbate and the atoms conforming the adsorbate surface. Chemical adsorption generally involves electron transfer between solid and liquid phases. Adsorption from solutions occurs because of differences in concentration (activities) in solution, and in the carbon pores. The adsorption process comprehends four steps. Three of these steps involve diffusion and the fourth one is adsorption:

- The molecule to be removed migrates from the bulk of the solution to the liquid layer surrounding the AC particle.

- The material has to migrate through the surface film to reach the outer surface of the carbon.

- Then, it must diffuse into the pores.

- Finally, the material will be adsorbed deep in the micropore region of the activated carbon.

- The experimental methodology adopted in the present study. It includes adsorption to evaluate the pollutants from distillery spent wash (wastewater). Activated carbon has been used as an adsorbent for the removal of COD, TDS, $\mathrm{pH}, \mathrm{DO}$.

\subsection{Sampling Location}

The water samples were brought from the industry "Wave distilleries and breweries private limited" located at village Ahmadpura, kali nadi, harduagunj, $16 \mathrm{~km}$ from Aligarh and analyzed for different parameters in the environmental engineering laboratory of civil engineering department, Z.H.C.E.T, Aligarh Muslim University, Aligarh, Uttar Pradesh, India. Dark plastic bottles of 2 liters capacity each with a stopper were used for collecting samples. Each bottle was washed with $2 \%$ nitric acid and then rinsed three times with distilled water. The bottles were then preserved in a clean place. The bottles were filled leaving no air space, and then the bottle was sealed to prevent any leakage and stored in a cool place. Each container was clearly marked with the name, location and date of sampling.

\subsection{Sample Characteristics}

The sample was collected directly from distillery effluent outlet pipe which is discharging the effluent into Kali nadi. Sample which was collected is colour less giving an unpleasant smell of like burnt sugar the temperature of the sample is high around $30^{\circ} \mathrm{C}$.

\subsection{Preparation of Sample Dilutions}

In order to check the effect of different dilutions of spent wash on removal efficiency of different pollutants and different type of heavy metals from the wastewater the spent wash has been diluted to three different dilutions i.e. $25 \%$ of sample, $50 \%$ of sample and $100 \%$ pure sample. Each dilution sample of $600 \mathrm{ml}$ quantity has been prepared taking $25 \%$ and $50 \%$ sample and diluting it to $600 \mathrm{ml}$ with distilled water. Third sample is pure spent wash of $600 \mathrm{ml}$ quantity.

\section{EXPERIMENTAL WORK AND ANALYSIS}

Experiment consists of adsorption carried out with different adsorbent dosage and contact time with the three different dilutions of sample as shown in Table1.

Adsorbent dosage of $2 \mathrm{~g}, 5 \mathrm{~g}$, and $10 \mathrm{~g}$ with the corresponding contact time of $6 \mathrm{hr}, 12 \mathrm{hr}$ and $24 \mathrm{hr}$ for each sample was used with each dilution. Each diluted sample of $600 \mathrm{ml}$ quantity is divided into three parts of $200 \mathrm{ml}$ quantity each. There are total nine samples three from each diluted sample of $200 \mathrm{ml}$ quantity each. Each concentrations each sample is taken in a volumetric flask of $250 \mathrm{ml}$ and added with a desired adsorbent dose. Each flask was shaken for one hour and the samples was filtered and collected for analysis after desired contact time. Whole adsorption test was performed at room temperature.

Table 1 Showing varying adsorbent dose with contact time at different dilutions

\begin{tabular}{|c|c|c|c|c|c|c|c|c|}
\hline Sample no. & \multicolumn{2}{|c|}{$25 \%$ dilution } & Sample no. & \multicolumn{2}{|c|}{$50 \%$ dilution } & Sample no. & \multicolumn{2}{c|}{$100 \%$ sample } \\
\hline & $\mathrm{Ad}(\mathrm{g})$ & $\mathrm{Ct}(\mathrm{hr})$ & & $\mathrm{Ad}(\mathrm{g})$ & $\mathrm{Ct}(\mathrm{hr})$ & & $\mathrm{Ad}(\mathrm{g})$ & $\mathrm{Ct}(\mathrm{hr})$ \\
\hline 1 & 1 & 6 & 1 & 1 & 6 & 1 & 1 & 6 \\
\hline 2 & 5 & 12 & 2 & 5 & 12 & 2 & 5 & 12 \\
\hline 3 & 10 & 24 & 3 & 10 & 24 & 3 & 10 & 24 \\
\hline
\end{tabular}

Ad: adsorbent dose (gram)

Ct: contact time (hour) 


\subsection{ANALYSIS OF SPENT WASH BEFORE}

\section{ADSORPTION}

Following are the parameters in a tabular form (Table 2) which were analyzed initially i.e. before adsorption for the three dilutions of $25 \%, 50 \%$ and $100 \%$ pure sample and with different adsorbent dose and contact time.

Table 2: Showing parameter analyzed before adsorption.

\begin{tabular}{|c|c|c|c|}
\hline Parameters & $\begin{array}{c}\text { For 25\% } \\
\text { sample } \\
\text { dilution }\end{array}$ & $\begin{array}{c}\text { For 50\% } \\
\text { sample } \\
\text { dilution }\end{array}$ & $\begin{array}{c}\text { For } \\
100 \% \\
\text { pure } \\
\text { sample }\end{array}$ \\
\hline $\mathrm{pH}$ & 5.4 & 5.99 & 4.29 \\
\hline $\mathrm{COD}(\mathrm{mg} / \mathrm{l})$ & 1200 & 2560 & 3200 \\
\hline
\end{tabular}

\begin{tabular}{|c|c|c|c|}
\hline $\mathrm{TDS}(\mathrm{mg} / \mathrm{l})$ & 361 & 491 & 675 \\
\hline $\mathrm{DO}(\mathrm{mg} / \mathrm{l})$ & 3.0 & 1.7 & 1.2 \\
\hline
\end{tabular}

\section{RESULTS AND DISCUSSION}

\subsection{Graphs after Adsorption}

The following graphs will give better illustration of the results obtained following the analysis of spent wash. Here the results obtained are graphically represented for various wastewater quality parameters.

For $25 \%$ Effluent Dilution

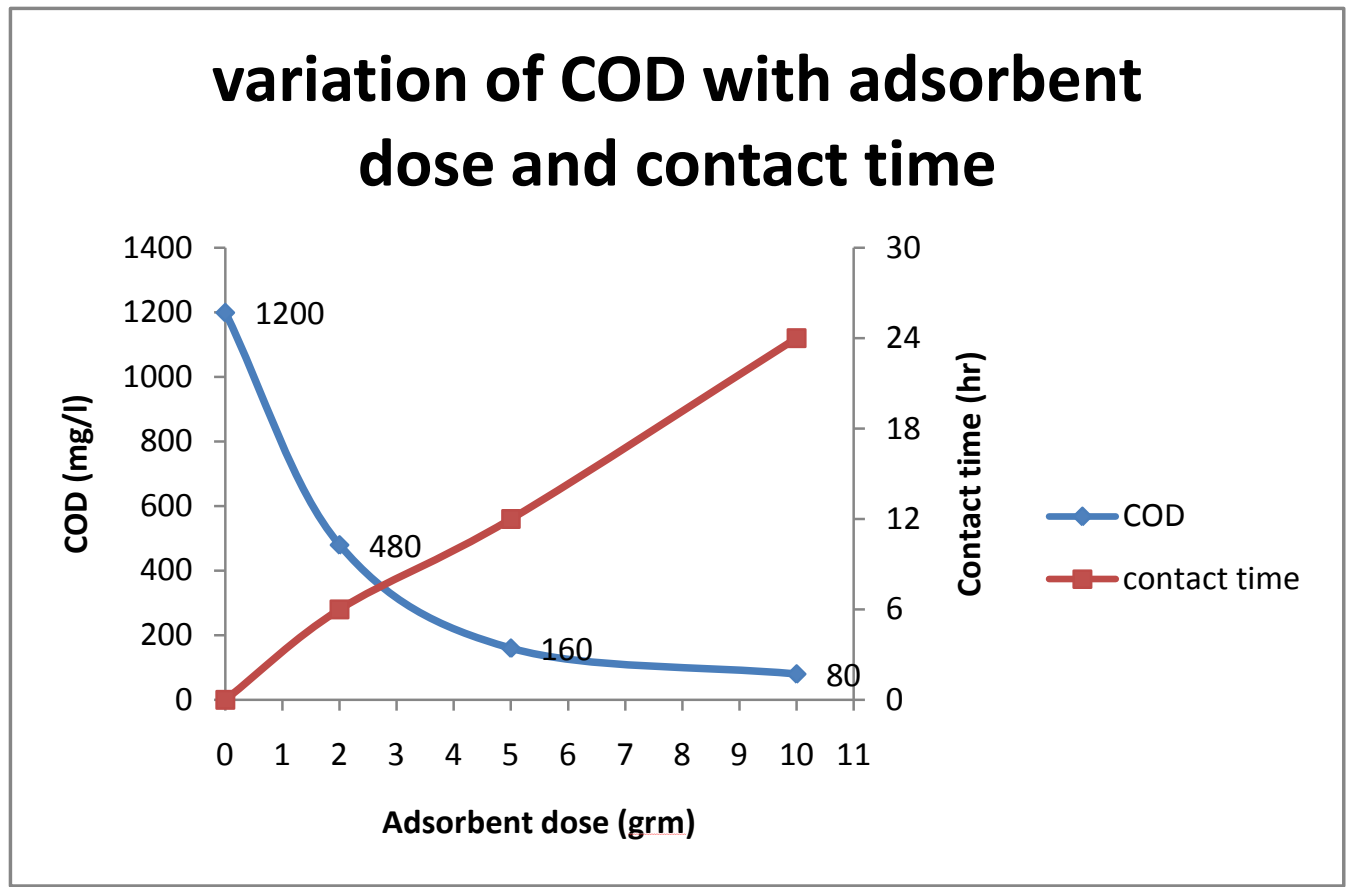

Fig 1: variation of COD with adsorbent dose and contact time

In Figure $1 \mathrm{COD}$ decreases with increase in adsorbent dose up to $10 \mathrm{gm}$ and contact time of $24 \mathrm{hr}$ and then attains a constant value with increase in adsorbent dose and contact time. The maximum percent removal $93.33 \%$ has been observed at an adsorbent dose of $10 \mathrm{gm} / 200 \mathrm{ml}$, contact time of $24 \mathrm{hr}$ with $25 \%$ diluted sample. The result can also be summarized in Table 3 . 


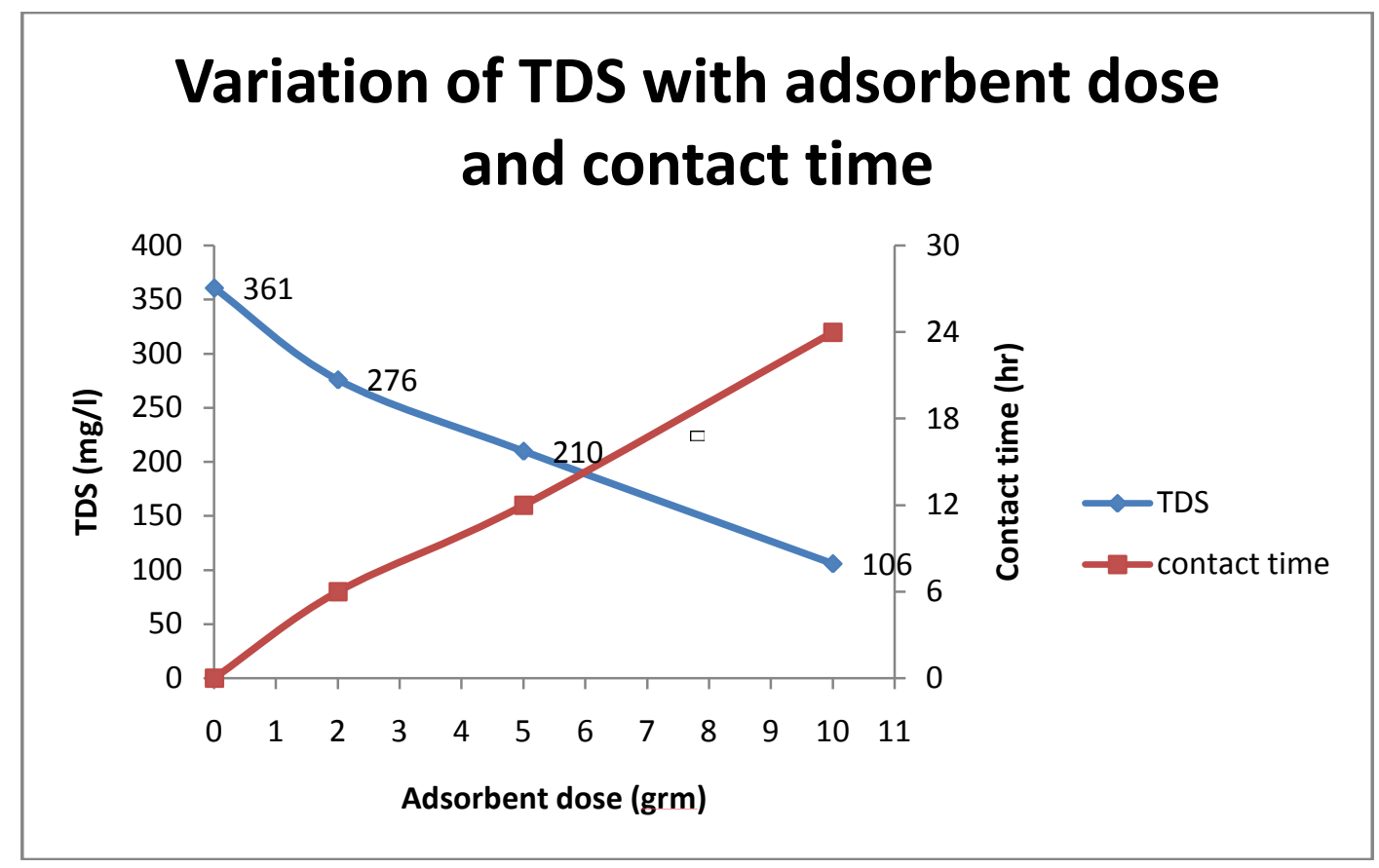

Fig 2: Variation of TDS with adsorbent dose and contact time

In Figure 2 TDS decreases with increase in adsorbent dose up to $10 \mathrm{gm}$ and contact time of $24 \mathrm{hr}$. The maximum percent removal $70.6 \%$ has been observed at an adsorbent dose of $10 \mathrm{gm} / 200 \mathrm{ml}$, contact time of $24 \mathrm{hr}$ with $25 \%$ diluted sample.

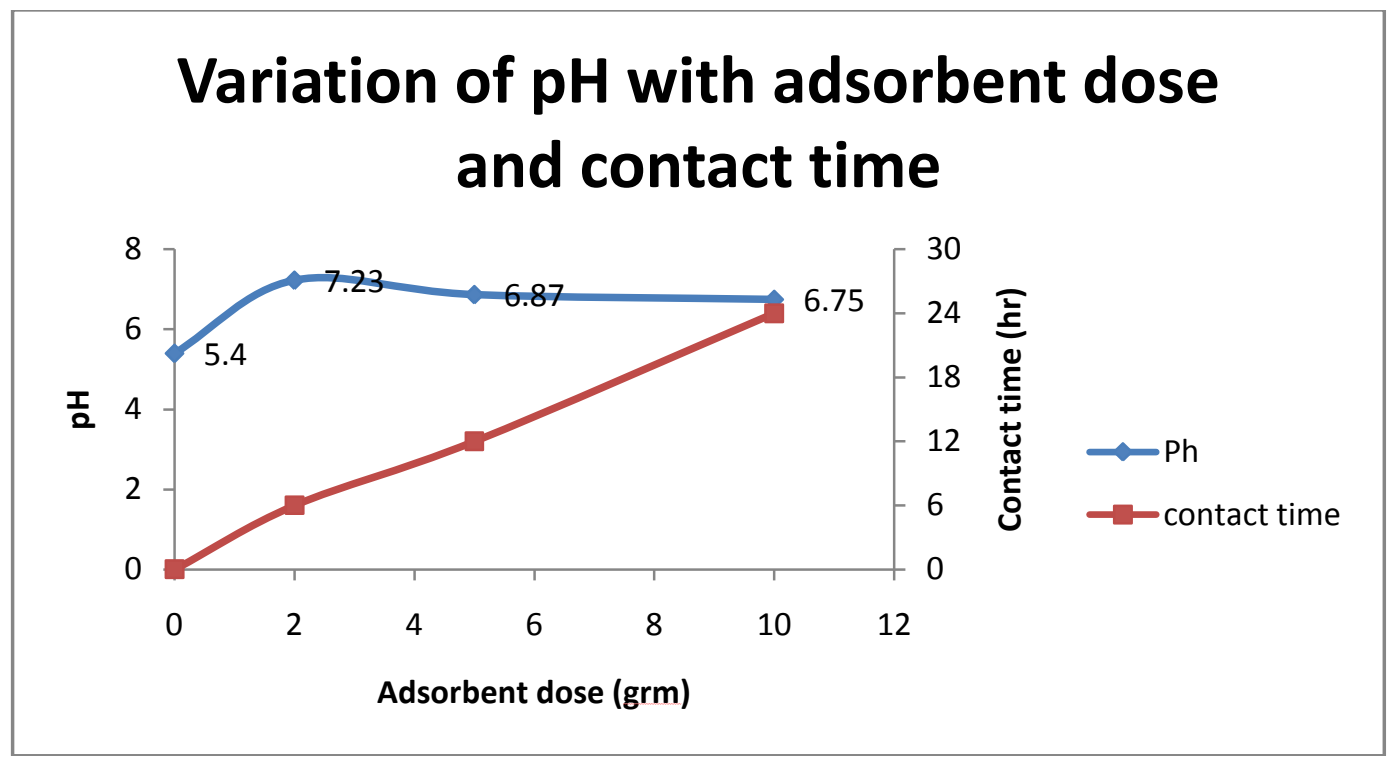

Fig 3: Variation of $\mathrm{pH}$ with adsorbent dose and contact time

In Figure $3 \mathrm{pH}$ increases with increase in adsorbent dose up to $2 \mathrm{gm}$ and contact time of $6 \mathrm{hr}$ and then decreases with increase in adsorbent dose and contact time. The maximum percent removal $25.31 \%$ has been observed at an adsorbent dose of $2 \mathrm{gm} / 200 \mathrm{ml}$ and contact time of $6 \mathrm{hr}$ with $25 \%$ diluted sample. 


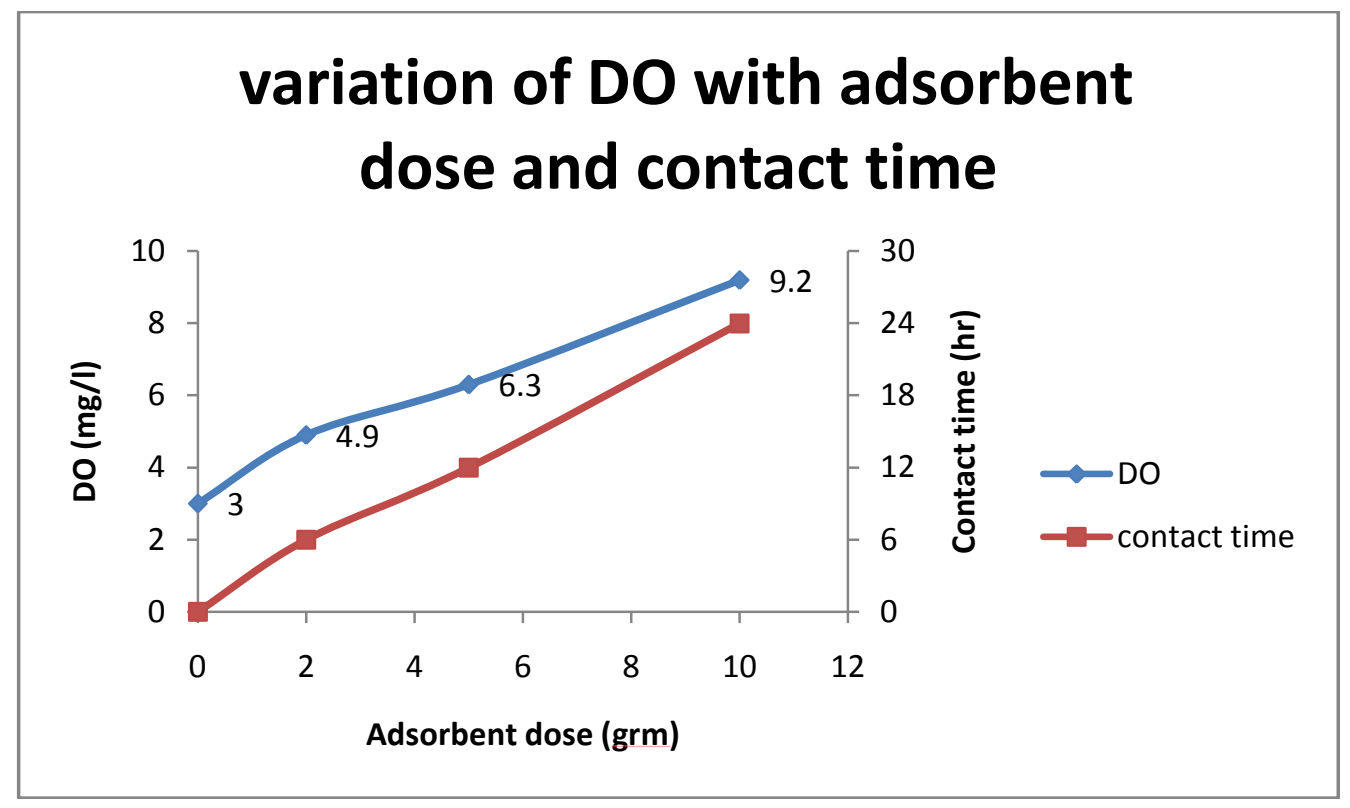

Fig 4: Variation of DO with adsorbent dose and contact time

In Figure 4 DO increases up to a maximum value of 9.2 with increase in adsorbent dose up to $10 \mathrm{gm}$ and contact time of $24 \mathrm{hr}$. The maximum percent removal $67.39 \%$ has been observed at an adsorbent dose of $10 \mathrm{gm} / 200 \mathrm{ml}$, contact time of $24 \mathrm{hr}$ with $25 \%$ diluted sample.

\section{For 50\% Effluent Dilution}

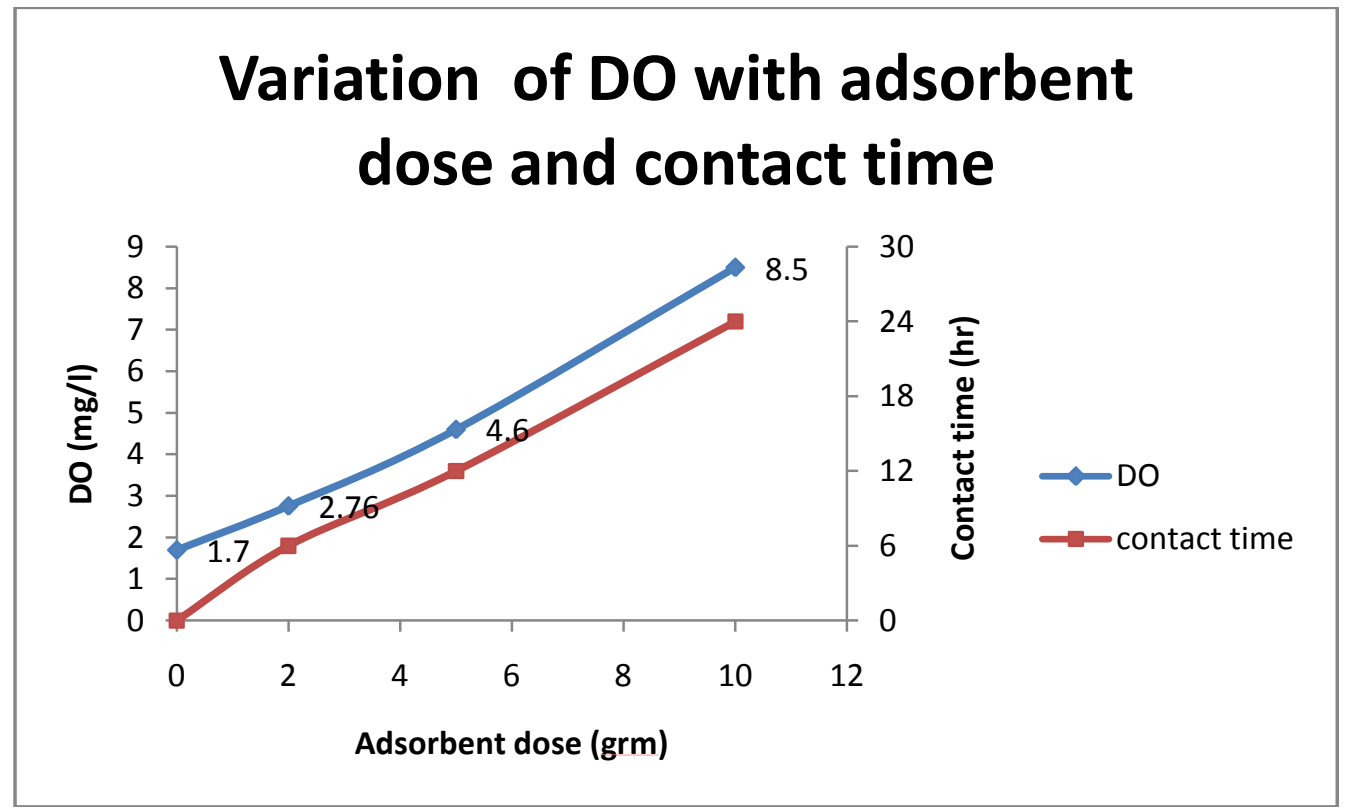

Fig 5: Variation of DO with adsorbent dose and contact time

In Figure 5 DO increases up to a maximum value of 8.5 with increase in adsorbent dose up to $10 \mathrm{gm}$ and contact time of $24 \mathrm{hr}$. The maximum percent removal $80 \%$ has been observed at an adsorbent dose of $10 \mathrm{gm} / 200 \mathrm{ml}$, contact time of $24 \mathrm{hr}$ with $50 \%$ diluted sample. The result can also be summarized in Table 4. 


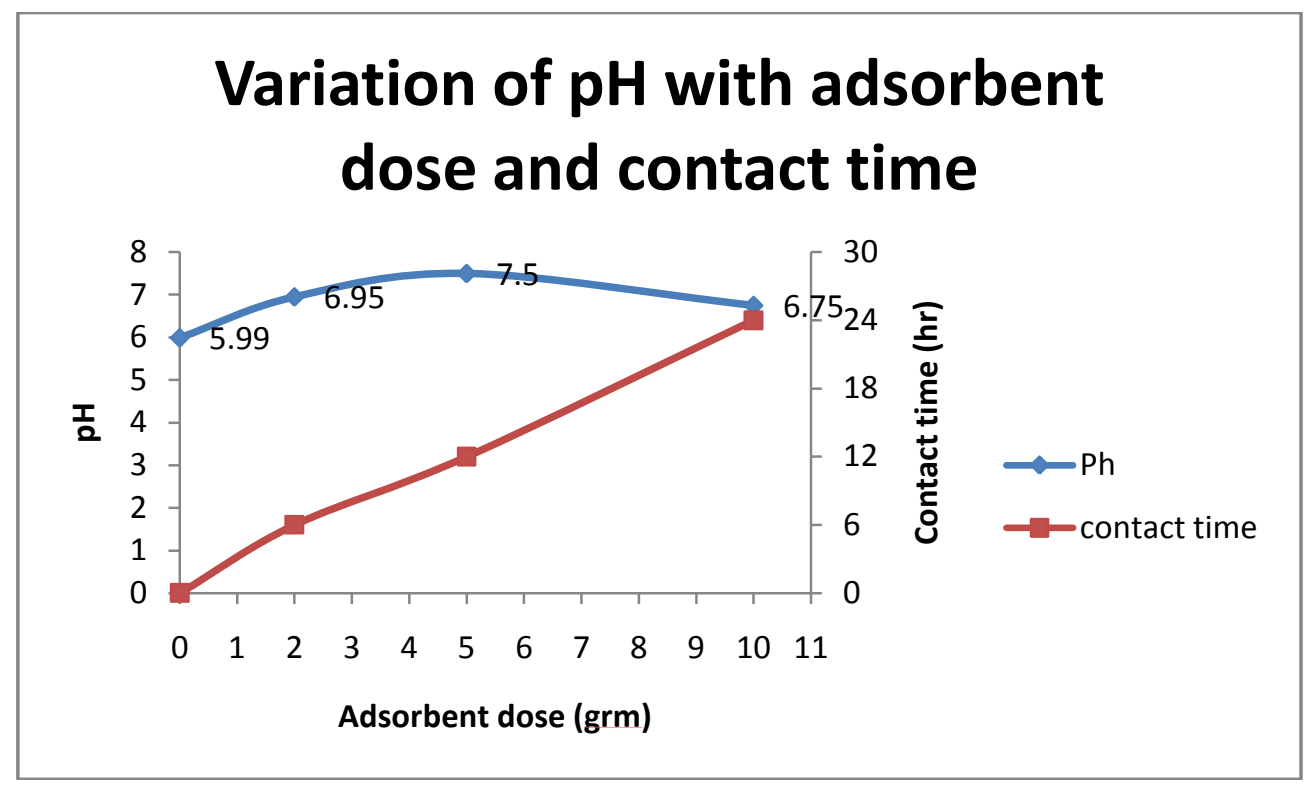

Fig 6: Variation of $\mathrm{pH}$ with adsorbent dose and contact time

In figure $6 \mathrm{pH}$ increases with increase in adsorbent dose up to $5 \mathrm{gm}$ and contact time of $12 \mathrm{hr}$ and then decreases with increase in adsorbent dose and contact time. The maximum percent removal $20.13 \%$ has been observed at an adsorbent dose of $5 \mathrm{gm} / 200 \mathrm{ml}$, contact time of $12 \mathrm{hr}$ with $50 \%$ diluted sample.

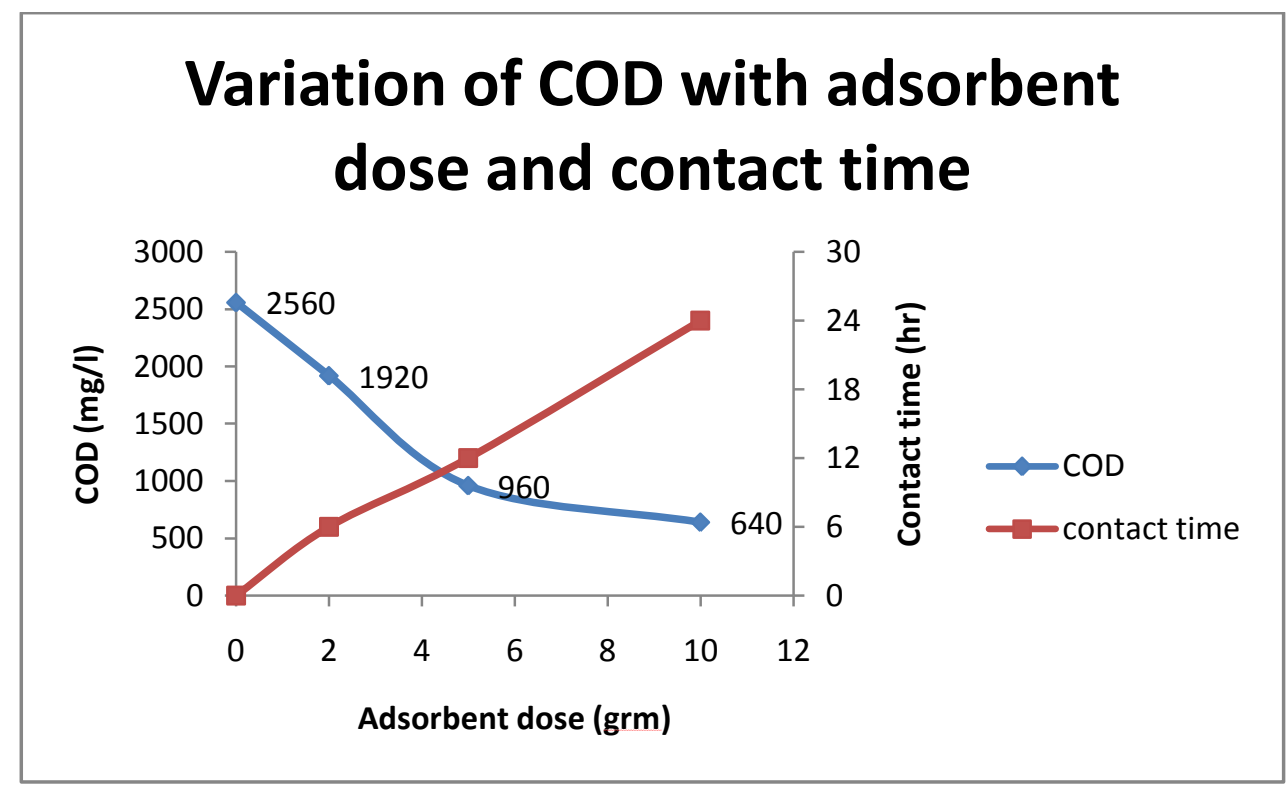

Fig 7: Variation of COD with adsorbent dose and contact time

In Figure 7 COD decreases with increase in adsorbent dose up to $10 \mathrm{gm}$ and contact time of $24 \mathrm{hr}$ and then attains a constant value with increase in adsorbent dose and contact time. The maximum percent removal $75 \%$ has been observed at an adsorbent dose of $10 \mathrm{gm} / 200 \mathrm{ml}$, contact time of $24 \mathrm{hr}$ with $50 \%$ diluted sample. 


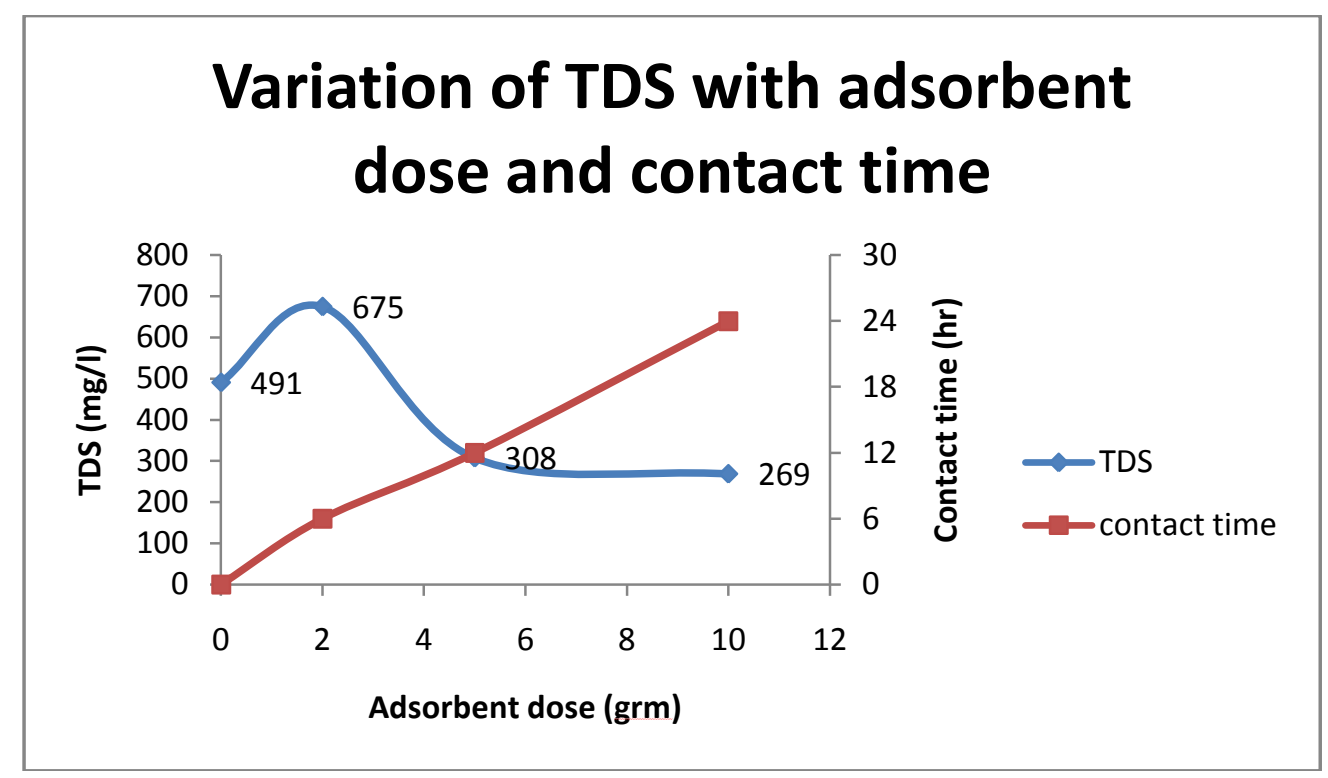

Fig 8: Variation of TDS with adsorbent dose and contact time

In Figure 8 TDS increases with increase in adsorbent dose up to $2 \mathrm{gm}$ and contact time of $6 \mathrm{hr}$ and then decreases with increase in adsorbent dose and contact time. The maximum percent removal $45.21 \%$ has been observed at an adsorbent dose of $10 \mathrm{gm} / 200 \mathrm{ml}$, contact time of $24 \mathrm{hr}$ with $50 \%$ diluted sample.

\section{For $100 \%$ Effluent Dilution}

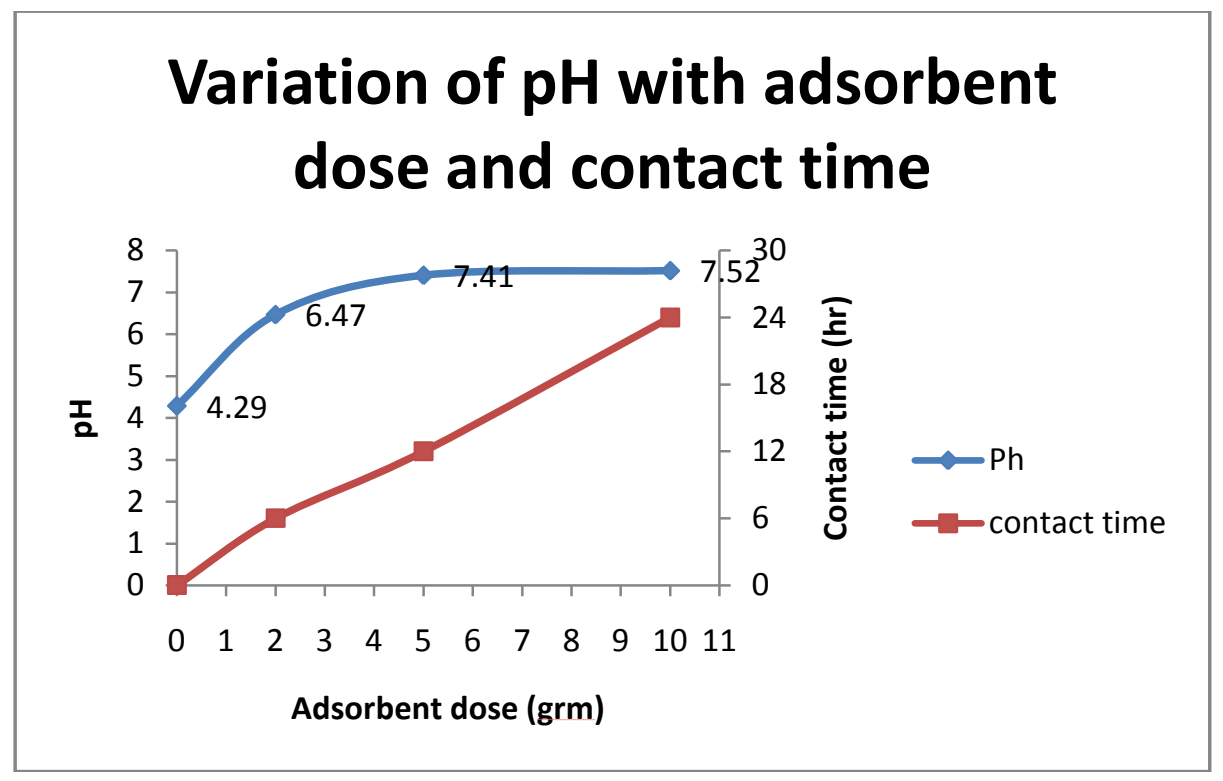

Fig 9: Variation of $\mathrm{pH}$ with adsorbent dose and contact time

In Figure $9 \mathrm{pH}$ increases with increase in adsorbent dose up to $5 \mathrm{gm}$ and contact time of $12 \mathrm{hr}$ and then there is not much effect with increase in adsorbent dose and contact time. The maximum percent removal $42.95 \%$ has been observed at an adsorbent dose of $10 \mathrm{gm} / 200 \mathrm{ml}$, contact time of $24 \mathrm{hr}$ with $100 \%$ pure sample. The result can also be summarized in Table 5. 


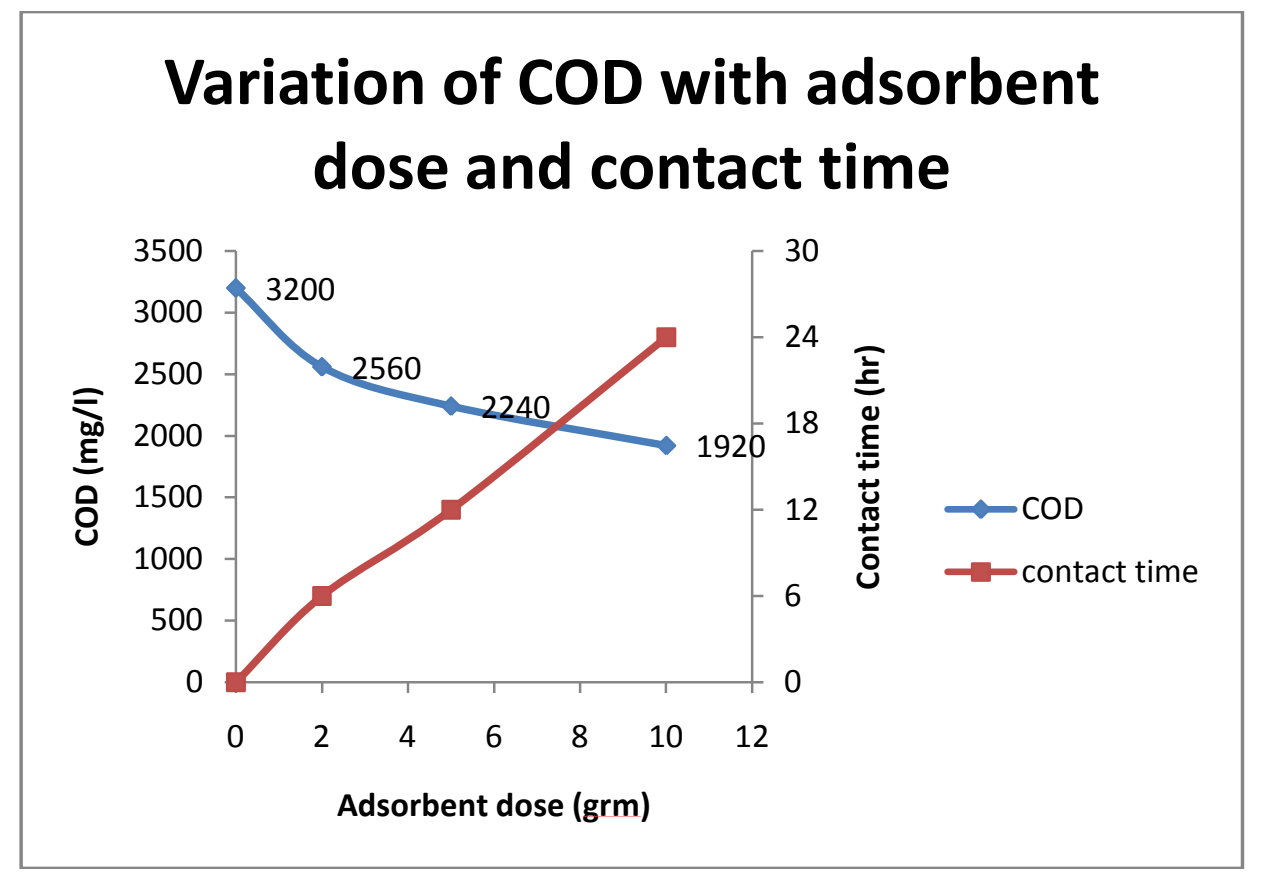

Fig 10: variation of COD with adsorbent dose and contact time

In Figure 10 COD decreases with increase in adsorbent dose up to $10 \mathrm{gm}$ and contact time of $24 \mathrm{hr}$ and then attains a constant value with increase in adsorbent dose and contact time. The maximum percent removal $40 \%$ has been observed at an adsorbent dose of $10 \mathrm{gm} / 200 \mathrm{ml}$, contact time of $24 \mathrm{hr}$ with $100 \%$ diluted sample.

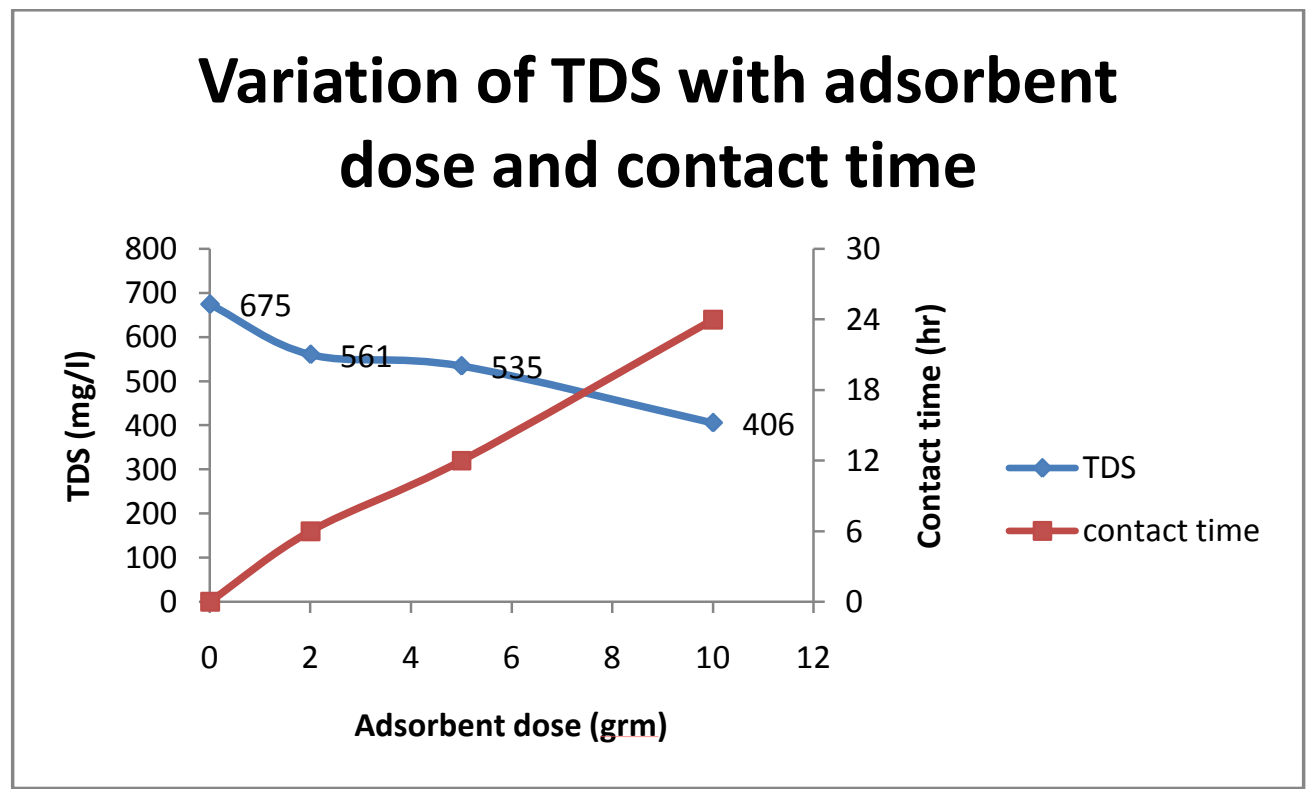

Fig 11: variation of TDS with adsorbent dose and contact time

In Figure 11 TDS decreases with increase in adsorbent dose up to $10 \mathrm{gm}$ and contact time of $24 \mathrm{hr}$ and then attains a constant value with increase in adsorbent dose and contact time. The maximum percent removal $39.85 \%$ has been observed at an adsorbent dose of $10 \mathrm{gm} / 200 \mathrm{ml}$, contact time of $24 \mathrm{hr}$ with $100 \%$ diluted sample. 


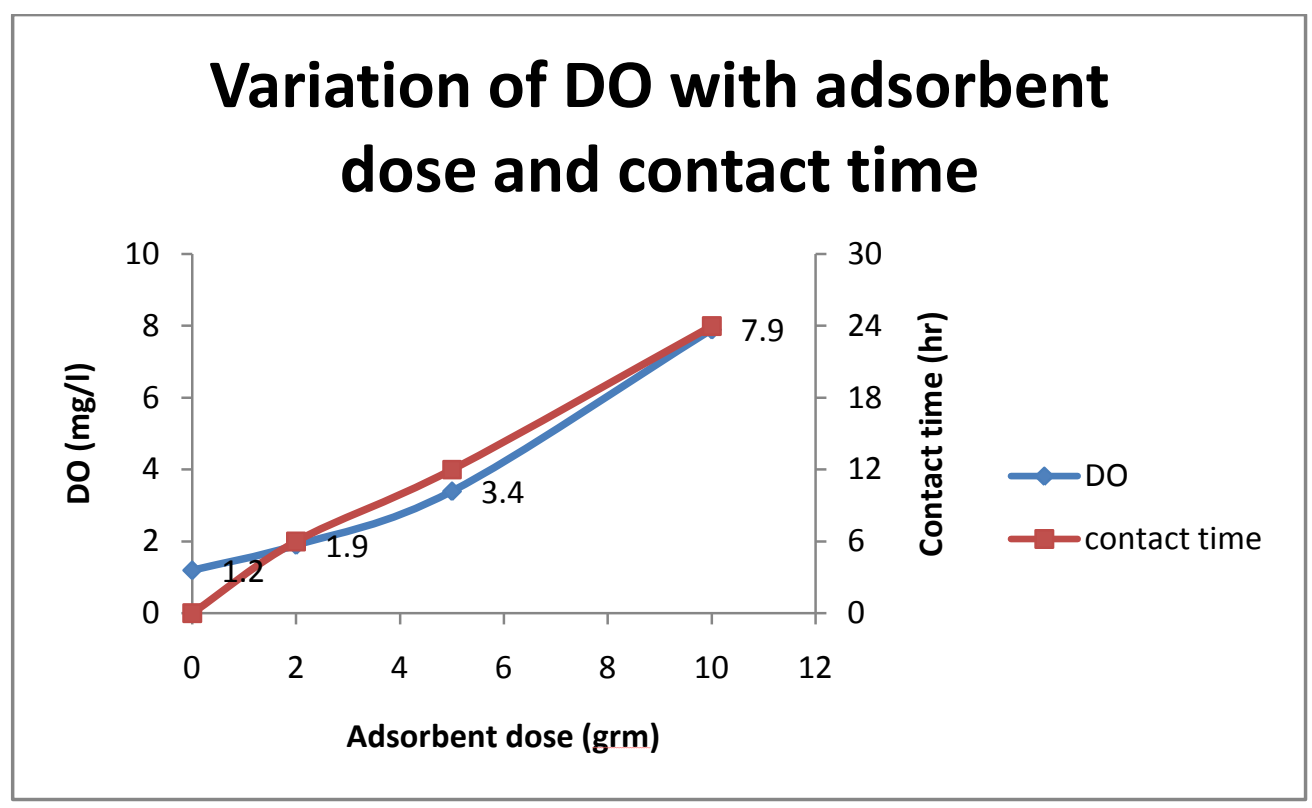

Fig 12: Variation of DO with adsorbent dose and contact time

In Figure 12 DO increases up to a maximum value of 7.9 with increase in adsorbent dose up to $10 \mathrm{gm}$ and contact time of $24 \mathrm{hr}$. The maximum percent removal $84.8 \%$ has been observed at an adsorbent dose of $10 \mathrm{gm} / 200 \mathrm{ml}$, contact time of $24 \mathrm{hr}$ with $100 \%$ diluted sample.

Table 3: Results analyzed from graphs for $25 \%$ sample dilution after adsorption

\begin{tabular}{|c|c|c|c|c|c|c|c|}
\hline \multirow{2}{*}{ Parameters } & \multicolumn{9}{|c|}{ For 25\% effluent dilution } \\
\cline { 2 - 8 } & Initial concentration & \multicolumn{2}{|c|}{ Final concentration after } & \multicolumn{3}{|c|}{ Removal(\%) after } \\
\cline { 2 - 8 } & & $6 \mathrm{hr}$ & $12 \mathrm{hr}$ & $24 \mathrm{hr}$ & $6 \mathrm{hr}$ & $12 \mathrm{hr}$ & $24 \mathrm{hr}$ \\
\hline $\mathrm{pH}$ & 5.4 & 7.23 & 6.87 & 6.75 & 25.31 & 21.39 & 20 \\
\hline $\mathrm{COD}(\mathrm{mg})$ & 1200 & 480 & 160 & 80 & 60 & 86.66 & 93.33 \\
\hline $\mathrm{TDS}(\mathrm{mg} /)$ & 361 & 276 & 210 & 106 & 23.54 & 41.82 & 70.6 \\
\hline $\mathrm{DO}(\mathrm{mg} / \mathrm{l})$ & 3.0 & 4.9 & 6.3 & 9.2 & 38.77 & 52.38 & 67.39 \\
\hline
\end{tabular}

Table 4: Results analyzed from graphs for $50 \%$ sample dilution after adsorption

\begin{tabular}{|c|c|c|c|c|c|c|c|}
\hline \multirow{2}{*}{ Parameters } & \multicolumn{7}{|c|}{ For 50\% effluent dilution } \\
\cline { 2 - 8 } & Initial concentration & \multicolumn{2}{|c|}{ Final concentration after } & \multicolumn{3}{|c|}{ Removal(\%) after } \\
\cline { 2 - 8 } & & $6 \mathrm{hr}$ & $12 \mathrm{hr}$ & $24 \mathrm{hr}$ & $6 \mathrm{hr}$ & $12 \mathrm{hr}$ & $24 \mathrm{hr}$ \\
\hline $\mathrm{pH}$ & 5.99 & 6.95 & 7.5 & 6.75 & 13.81 & 20.13 & 11.25 \\
\hline $\mathrm{COD}(\mathrm{mg} / \mathrm{l})$ & 2560 & 1920 & 960 & 640 & 25 & 62.5 & 75 \\
\hline $\mathrm{TDS}(\mathrm{mg} / \mathrm{l})$ & 491 & 675 & 308 & 269 & 27.25 & 37.27 & 45.21 \\
\hline $\mathrm{DO}(\mathrm{mg} / \mathrm{l})$ & 1.7 & 2.76 & 4.6 & 8.5 & 38.4 & 63.04 & 80 \\
\hline
\end{tabular}


Table5: Results analyzed from graphs for 100\% pure sample after adsorption

\begin{tabular}{|c|c|c|c|c|c|c|c|}
\hline \multirow{2}{*}{ Parameters } & \multicolumn{4}{|c|}{ For 100\% sample } \\
\cline { 2 - 8 } & Initial concentration & \multicolumn{3}{|c|}{ Final concentration after } & \multicolumn{3}{c|}{ Removal(\%) after } \\
\cline { 2 - 8 } & & $6 \mathrm{hr}$ & $12 \mathrm{hr}$ & $24 \mathrm{hr}$ & $6 \mathrm{hr}$ & $12 \mathrm{hr}$ & $24 \mathrm{hr}$ \\
\hline $\mathrm{pH}$ & 4.29 & 6.47 & 7.41 & 7.52 & 33.69 & 42.10 & 42.9 \\
\hline $\mathrm{COD}(\mathrm{mg} / \mathrm{l})$ & 3200 & 2560 & 2240 & 1920 & 20 & 30 & 40 \\
\hline $\mathrm{TDS}(\mathrm{mg} / \mathrm{l})$ & 675 & 561 & 535 & 406 & 16.88 & 20.74 & 39.8 \\
\hline $\mathrm{DO}(\mathrm{mg} / \mathrm{l})$ & 1.2 & 1.9 & 3.4 & 7.9 & 36.84 & 64.70 & 84.8 \\
\hline
\end{tabular}

\subsection{Discussion}

The results which are obtained after treatment of distillery spent wash most of which are within the permissible limits. The characteristic of spent wash do not allow its discharge into a water body, hence it requires treatment. Biological treatment, especially with pure cultures, appears promising and possibly cost-effective for color removal; however, the initiatives are mainly confined to laboratory trials. Adsorbents like activated carbon that result in almost complete decolourisation are not cost effective for treating the enormous volumes of spent wash typically generated in a distillery. Thus, there is scope for examining low cost adsorbents, including wastes generated in other industrial processes / operations. The production of distillery must be incorporated in the design to accommodate the increased amount of effluent. Extensive research has been conceded out on healing of distillery wastes in many parts of the world. Effluent in an organic nutrient solution, it has a wide spectrum of utility. There have been some attempts to use spent wash as substrate for yeast growth or for biochemical production.

Table 6: Final results in a tabular form

\begin{tabular}{|c|c|c|c|c|}
\hline Pollutants & Sample Dilution \% & Adsorbent dose (gram) & Contact time (hr) & \% Removal \\
\hline $\mathrm{pH}$ & $100 \%$ & 10 & 24 & 42.95 \\
\hline $\mathrm{COD}$ & $25 \%$ & 10 & 24 & 93.33 \\
\hline $\mathrm{TDS}$ & $25 \%$ & 10 & 24 & 70.6 \\
\hline $\mathrm{DO}$ & $100 \%$ & 10 & 24 & 84.8 \\
\hline
\end{tabular}

\section{BASED ON THE EXPERIMENTS PERFORMED， THE FOLLOWING \\ CONCLUSIONS ARE DRAWN}

1. The activated carbon is found to be effective adsorbent.

2. It has been observed that adsorbent dose of 10 gram and contact time of $24 \mathrm{hr}$ for $200 \mathrm{ml}$ of sample is found to be most effective for different dilutions for removal of most pollutants.

3. While for removal of heavy metals, adsorbent dose of 5 gram and contact time of $12 \mathrm{hr}$ found to be most effective.

4. On increasing the adsorbent dose and contact time after this limit there is not much effect on the removal of pollutants and heavy metals.

5. This is because of the adsorptive capacity of the adsorbent is reached to an end.
6. The adsorbent dosage, $\mathrm{pH}$, contact time and initial concentration of organic matter have significant effect on the COD removal and dissolved oxygen.

7. The maximum removal $(42.95 \%)$ of $\mathrm{pH}$ has been observed at $10 \mathrm{gm} / 200 \mathrm{ml}$ of adsorbent dose and a contact time of $24 \mathrm{hr}$ for $100 \%$ pure sample.

8. The maximum removal $(93.33 \%)$ of COD has been observed at $10 \mathrm{gm} / 200 \mathrm{ml}$ of adsorbent dose and a contact time of $24 \mathrm{hr}$ for $25 \%$ diluted sample.

9. The maximum removal $(70.6 \%)$ of TDS has been observed at $10 \mathrm{gm} / 200 \mathrm{ml}$ of adsorbent dose and a contact time of $24 \mathrm{hr}$ for $25 \%$ diluted sample.

10. The maximum removal $(84.8 \%)$ of DO has been observed at $10 \mathrm{gm} / 200 \mathrm{ml}$ of adsorbent dose and a contact time of $24 \mathrm{hr}$ for $100 \%$ pure sample.

11. It is also found that there is a certain limit for increasing the adsorbent doses for given amount of effluent. This has to be carefully controlled. An excess use can leads to uneconomical process. The initial 
concentration plays an important role throughout the adsorption.

12. Regeneration and disposal depends on the amount and the availability of the adsorbent.

\section{REFERENCES}

[1] Sunil J. Kulkarni, Suhas V Patil, and Y. P. Bhalerao "Fly ash adsorption studies for organic matter removal accompanying increase in dissolved oxygen".

[2] Vernon L. Snoeyink, Ph.D. \& R. Scott Summers, Ph.D. "adsorption of organic compounds".

[3] European business and technology centre: European Union: association of European chambers of commerce and industry.

[4] J.S. Kamyotra and R.M. Bhardwaj "Municipal wastewater management in India".

[5] Milind R.Gidde, Julie Dutta', Snehal Jadhav "Comparative adsorption studies on activated rice husk and rice husk ash by using methylene blue as dye".

[6] Technologies for the treatment of molasses based distillery effluents.

[7] Technical EIA guidance manual for distilleries.

[8] Keith R. du Plessis "Community-level analysis of the microbiology in constructed wetlands treating distillery effluent".

[9] Lt Col Mantha Nagaraj, Dr Arvind Kumar "distillery wastewater treatment and disposal".

[10] Z.V.P. murthy, L.B. chaudhari "Treatment of distillery spent wash by combined UF AND RO process".

[11] Namita Tewari, V K Verma and J P N Rai "Comparative evaluation of natural adsorbent for pollutants removal from distillery spent wash"

[12] Dinesh Mohan, Charles U. Pittman Jr. "Arsenic removal from water/wastewater using adsorbents-A critical review".

[13] Sunil J. Kulkarni, Suhas V Patil, and Y. P. Bhalerao "Flyash adsorption studies for organic Matter Removal Accompanying Increase in dissolved oxygen"

[14] Mojtaba Hadavifar, Habibollah Younesi, Aliakbar Zinatizadeh "Application of ozone and granular activated carbon for distillery effluent treatment".

[15] Bhise R.M., Patil A.A., Raskar A.R., Patil P.J. and Deshpande D.P. "Removal of colour of spent wash by activated charcoal adsorption and electro coagulation".

[16] Pawar Avinash Shivajirao "Treatment of distillery waste water using membrane technology".

[17] Sandeep K. Pandey, Anil K. Gupta, M. Yunus "Physico-chemical analysis of treated distillery effluent irrigation responses on crop plants pea (Pisum sativum) and wheat (Triticum aestivum)".

[18] Gupta, Sunil Kumara, Gupta, S. K.b, Singh, Gurdeep "Biodegradation of distillery spent wash in anaerobic hybrid reactor".

[19] C.B. Shivayogimath, T.K. Ramanujam "Treatment of distillery spent wash by hybrid UASB reactor".
[20] Parmesh Kumar Chaudhari, Indra Mani Mishra, Shri Chand "Decolourization and removal of chemical oxygen demand (COD) with energy recovery Treatment of biodigester effluent of a molasses-based alcohol distillery using inorganic coagulants".

[21] Y. Satyawali, M. Balakrishnan "Wastewater treatment in molasses-based alcohol distilleries for COD and colour removal".

[22] Deepak Pant a, Alok Adholeya "Biological approaches for treatment of distillery wastewater".

[23] William Camargo N. "Evaluation of Activated Carbon for Treating Heavy Metals in Aquaculture".

[24] S.N. Pandey, B.D. Nautiyal and C.P. Sharma "Pollution level in distillery effluent and its phototoxic effect on seed germination and early growth of maize and rice".

[25] Xolisa Lorraine Melamane 2006 "treatment of wine distillery wastewaters by high rate anaerobic digestion and submerged membrane systems"

[26] Technology information, forecasting and assessment council: department of science and technology govt. of India.

[27] $\mathrm{P}$ j strong "fungal remediation of distillery and winery wastewater".

[28] K. Vasanth Kumar, K. Subanandam, V. Ramamurthi and S. Sivanesan "solid liquid adsorption for wastewater treatment: principle design and operation". 